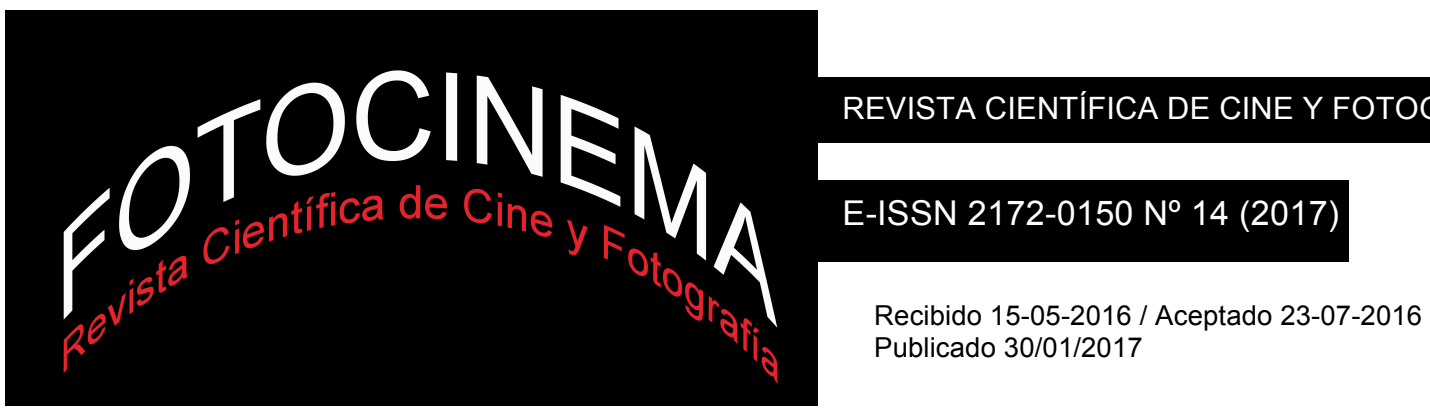

\title{
KAMEI FUMIO. \\ SOMBRAS, MISERIAS Y CENSURA EN EL CINE DOCUMENTAL JAPONÉS
}

\section{KAMEI FUMIO. SHADOWS, MISERIES AND CENSORSHIP IN THE JAPANESE DOCUMENTARY FILM}

Adrián Tomás Samit

Universidad Nacional de Gyeonsang, Corea del Sur atomsamit@gmail.com

\begin{abstract}
Resumen:
Kamei Fumio (1908-1987) fue un documentalista japonés que a lo largo de toda su carrera sufrió la censura. No fue hasta finales del siglo XX cuando su obra comenzó a ser recuperada. Sus películas, innovadoras tanto en la puesta en escena como en el montaje, contenían un mensaje crítico e incómodo para el gobierno japonés. En sus comienzos tomó una postura poética y antibelicista al tratar la guerra sino-japonesa. Finalizada la Segunda Guerra Mundial su crítica se cernió sobre los dirigentes japoneses. En su última etapa se centró en las consecuencias de los bombardeos nucleares y en la discriminación de las clases bajas japonesas. Para sobrevivir en la industria también tuvo que realizar películas de propaganda en contra de sus ideales. La obra de Kamei Fumio es un signo de los tiempos, de cómo trata la historia a un cineasta molesto para quienes la escriben. Sus películas, un hito desconocido.
\end{abstract}

\begin{abstract}
:
Kamei Fumio (1908-1987) was a Japanese documentary filmmaker who throughout his career suffered censorship. It was not until the late 20th century that his work began to be recovered. His films, innovative with the mise-en-scène and the editing, contained a critical and uncomfortable message for the Japanese government. In the beginning of his career he took a poetic and antiwar attitude in dealing with the Sino-Japanese War. After the Second World War he criticized Japanese leaders. In his last period, Kamei focused on the consequences of the nuclear bombings and discrimination of Japanese lower classes. To survive in the industry also had to make propaganda films against his ideals. The work of Fumio Kamei is a sign of the times; it is about how the history treats an annoying filmmaker for those who write it. His films are an unknown milestone.
\end{abstract}

Palabras clave: Cine de propaganda; documental japonés; Kamei Fumio; cine bélico; Hiroshima; censura.

Keywords: Propaganda Film; Japanese Documentary; Kamei Fumio; War Movies; Hiroshima; Censorship. 
Hay razones concretas por las que los extranjeros nunca han tenido noticia de la filmografía de Kamei, aparte de la inclinación occidental por asumir que Europa y América acapararon rápidamente la producción. Primero [...] cuando Kamei estaba realizando sus películas más importantes [durante la Segunda Guerra Mundial] era el enemigo. [...] Probablemente el mayor golpe a la reputación de Kamei fuera de Japón ha venido de su desafortunado rechazo en el monumental trabajo de Donald Richie y Joseph Anderson The Japanese Film: Art and Industry (1959) [...] donde básicamente reducen todo el documental japonés de preguerra y bélico a mera propaganda (Nornes, 2001, p. 43) ${ }^{1}$.

\section{Nuevas (y necesarias) miradas}

La historia del cine documental, por cuestiones como el reconocimiento, la geografía, la filiación política o los análisis fundacionales, entre otras, se ha estudiado de manera delimitada. España no es una excepción. Fuera han quedado no solo cineastas, también cinematografías que aportan un punto de vista diferente y esencial a un género cinematográfico donde la diversidad de voces es la que le otorga su principal valor. Tener en España tres festivales de cine documental reconocidos internacionalmente, que con suerte publicarán algún libro como primera, única, y quizás última aproximación a esos otros cines, y que el análisis del documental no cese de repetir nombres y conceptos nos atrapa en un bucle tanto teórico como práctico.

En el año 1938 el montador Kamei Fumio² (1908-1987) realiza su primera película reconocida: Shanhai - shina jihen kōhō kiroku. Con apariencia de documental de propaganda, el film logra un acercamiento al conflicto sinojaponés que apunta a lo que será una filmografía de inicios vanguardistas, a contracorriente y esencial, cuyo mayor (y desconocido) ejemplo es Tatakau heitai (1939). El cine de Kamei Fumio es uno de los muchos ejemplos de

\footnotetext{
${ }^{1}$ La traducción de las citas en inglés, si no se indica lo contrario, es propia.

2 Todos los nombres de origen japonés que aparecen en el texto siguen el orden propio:

2 Todos los nombres de origen japonés que aparecen en el texto siguen el orden propio: Apellido Nombre.
} 
discriminación cinematográfica que ha sufrido la historia. Únicamente Abé Mark Nornes (Universidad de Michigan) se ha acercado debidamente a esta figura. En España apenas hemos comenzando a analizar el documental japonés ${ }^{3}$, y en la mayoría de los casos mediante un análisis generalista donde films y cineastas son parte de un listado histórico antes que de un trabajo analítico. Así pues, demos un paso más en la construcción de este imaginario a través del seguimiento biofilmográfico de una figura concreta que recorrer la historia de un género.

Los principales temas que este análisis va a abordar son la experimentación dentro del género documental y su hibridación con el ensayo y la ficción de una manera pionera para su época; y la problemática de la censura y las diferentes formas de castigo ante un discurso político crítico, que han hecho de la filmografía de Kamei Fumio un objeto de interés lleno de innovaciones y contradicciones. Para llevar a cabo el análisis haremos un recorrido biográfico deteniéndonos en aquellos films más destacados mediante un análisis textual que nos permita leer e interpretar las imágenes debidamente.

\section{De la pintura al montaje cinematográfico}

Kamei Fumio nació el año 1908 en la prefectura de Fukushima. Influenciado por su padre, activista político del Movimiento por la libertad y los derechos del pueblo (Jiyū Minken Undō, 1874-1890), Kamei maduró un enérgico compromiso político que le llevó a dejar la escuela y marcharse a la Unión Soviética (URSS) en 1928 para estudiar pintura. Ese mismo año Pudovkin realizó Tempestad sobre Asia (Potómok Chinguiz-Jana) y Eisenstein Octubre (Октябрь). En 1929 llegaría El hombre de la cámara (Chelovek s kino-apparatom, Dziga Vertov). Nos encontramos en plena ebullición del cine soviético y la defensa de que "el perfeccionamiento del montaje en tanto que medio esencial de producir un efecto, es el axioma

3 Los únicos análisis realizados que hemos podido encontrar son los de Ana María Sedeño, Marian Moya, Marcos Centeno y el libro editado por el Festival Punto de Vista, todos ellos referidos en el apartado de bibliografía. 
indiscutible sobre el que se ha basado el desarrollo del cine" (Eisenstein et al.,1928, p. 1), tal y como firmaron Eisenstein, Pudovkin y Alexandrov en el Manifiesto del contrapunto sonoro. Así pues, Kamei no tardó en centrar su interés en el séptimo arte, dejó de lado sus estudios de pintura y entró en la escuela de cine de Leningrado, donde el montaje y sus implicaciones políticas fueron su principal tema de estudio.

En 1931, debido a sufrir de tuberculosis y conminado por su madre, Kamei volvió a Japón dejando a una mujer y a un hijo en la URSS. Más adelante trató de regresar, pero el gobierno japonés le denegó el visado. Sin más remedio que permanecer en Japón, con la ayuda de un amigo entró a trabajar para el PCL (Photo Chemical Laboratory), que en 1936 se convirtió en Toho Studio, y comenzar así su carrera en el cine mediante la escritura de guiones y el montaje de películas de “relaciones públicas” (Nornes, 2003, p. 150), o dicho de otra manera: películas de propaganda.

Siguiendo esta línea, Toho decidió llevar a cabo una trilogía de ciudades en las que Japón estaba luchando durante la segunda guerra sino-japonesa (1937-1945). Dos de ellas estuvieron a cargo de Kamei Fumio. La primera, Shanhai (1938) y la tercera, Běijīng (1938). La segunda, Nankin (1938) fue obra de Akimoto Takeshi. En Shanhai, Kamei se hizo cargo voluntariamente del material que Miki Shigeru filmó in situ. Esto es debido a que la pretensión de Toho de mostrar una ciudad brillante que ha entrado en periodo de reconstrucción no quedó reflejado en las fantasmagóricas y depresivas imágenes que Miki enviaba. Esto le dio a Kamei la oportunidad de desarrollar una mirada personal y crítica que supondría el comienzo de su particular viacrucis por la industria cinematográfica a la contra del gobierno japonés.

En un artículo publicado en la revista Eiga Hyōron que Nornes (2003, p. 155) recoge, Kamei diferenció ambas películas calificando a Shanhai como su "tragedia” y a Běijīng como su "historia de amor". La primera todavía conserva una estructura y recursos de estilo del cine propagandístico del periodo, pero se puede apreciar en ella esa voluntad autoral y antibelicista, lo que la convierte en las más apropiada para un análisis sintético y claro. 
El film comienza con planos generales de la ciudad acompañados de música regional, mapas animados que describen los hechos (F1) y una voz narradora-guía típica. Un inicio que nos retrotrae a Tierra de España (The Spanish Earth, Joris Ivens, 1937), película considerada paradigmática del género y en la que encontramos los mismos elementos. Pronto, estos recursos irán cediendo ante un film abanico donde encontramos destellos del futuro cinéma vérité o incluso del neorrealismo italiano, una narrativa poética acorde al cine experimental, un montaje constructivista que guarda la crítica velada y una sinceridad absoluta de quién está detrás del montaje de las imágenes para con su propósito.

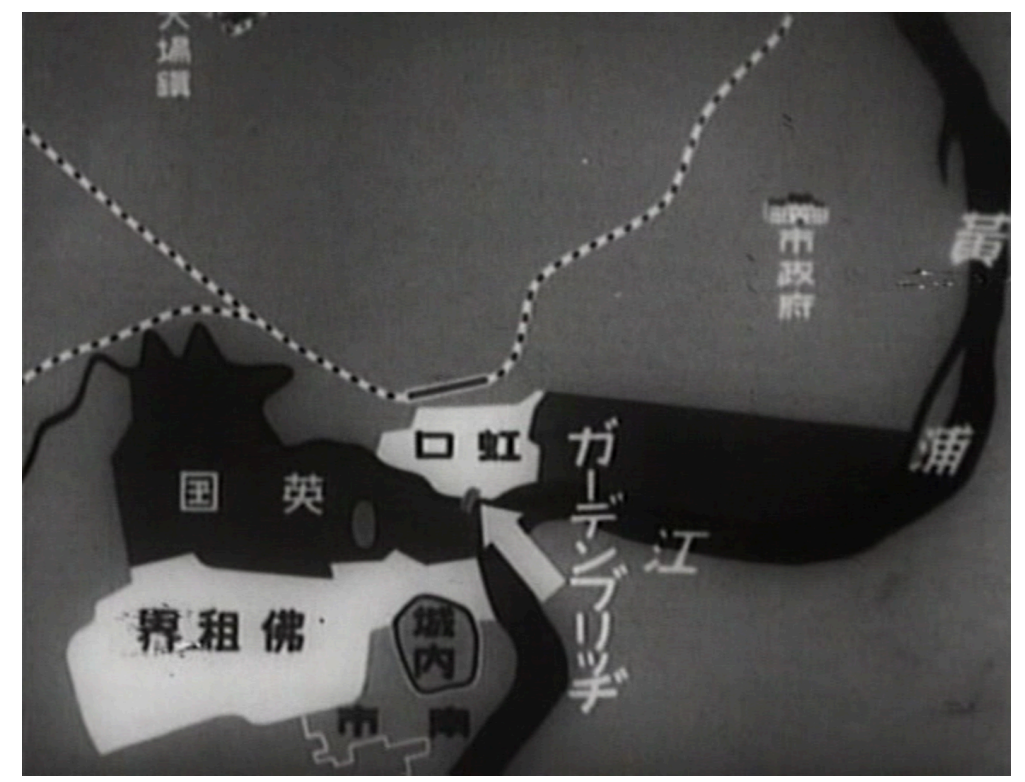

F1. Shanhai (Kamei Fumio, 1938).

El recurso que más sorprende por su uso es el sonido directo y la voz del narrador. El film cuenta con un narrador extradiegético, como la voz de Orson Welles (reemplazada posteriormente por la de Hemingway) en el film de Ivens. Algo habitual. Pero esta voz irá despareciendo entre las de los niños de la escuela, los refugiados chinos, los militares japoneses y la de un francés que pertenece a lo que parece el Ejercito de Salvación, y que aparecen siendo entrevistados o dialogando entre ellos, siendo al final la voz del narrador la que menos importancia tiene para la narración. Una escena parece estar planificada por Jean Rouche años antes de su Chronique d'un été (Crónica de un verano, 1960). En ella vemos y escuchamos a varios 
soldados sentados y dialogando de una manera en la que se puede intuir la presencia del cámara proponiendo debate (F2). También, un par de personajes se dirigen a cámara para comentar sus impresiones. A Kamei la humanidad de sus personajes le interesa más que la guerra y su desarrollo, convirtiendo el drama en algo personal y más cercano al espectador.

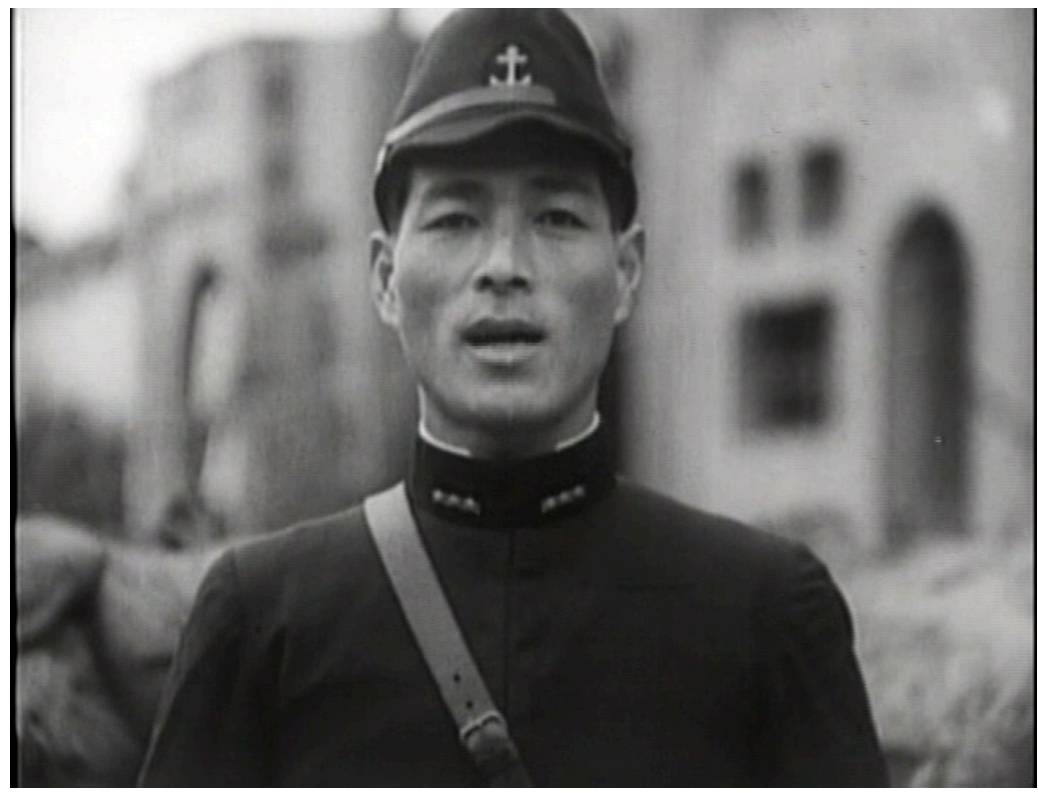

F2. Shanhai (Kamei Fumio, 1938).

En el film, tan importante es el soldado como el ciudadano chino sometido. Esto es clave, pues la película es propaganda a cargo del imperialismo japonés, que vencedor del conflicto quiere mostrar una imagen de solidaridad con los vencidos y de progreso en las ciudades conquistadas. Es aquí donde Kamei convierte el montaje en un arma crítica de doble filo. Akimoto Takeshi lo definió como “[...] absolutamente sorprendente... en América montar significa $2+2=4$, está todo claramente explicado de principio a fin, pero Kamei deja de explicar en el 2+2 y hace que el espectador saqué la respuesta... [...] recibiendo una sensación más fuerte y conmovedora" (Nornes, 2003, p. 155). Es significativo el tramo final, donde vemos a los soldados japoneses jugar con los niños, dando raciones de arroz a las mujeres y suministrando el consumo de agua. Estas escenas culminan con el plano de un soldado con un cordero en brazos. Seguidamente, el plano del francés con una niña. Y por si quedan atisbos de dudas del mensaje de represión que Kamei quiere comunicar, el plano que cierra la 
película es tan perturbador como clarividente: un perro con los ojos cerrados a los pies de un soldado, y reencuadrado por otro que de espaldas vigila la retaguardia $\left(\mathrm{F}_{3}\right)$.

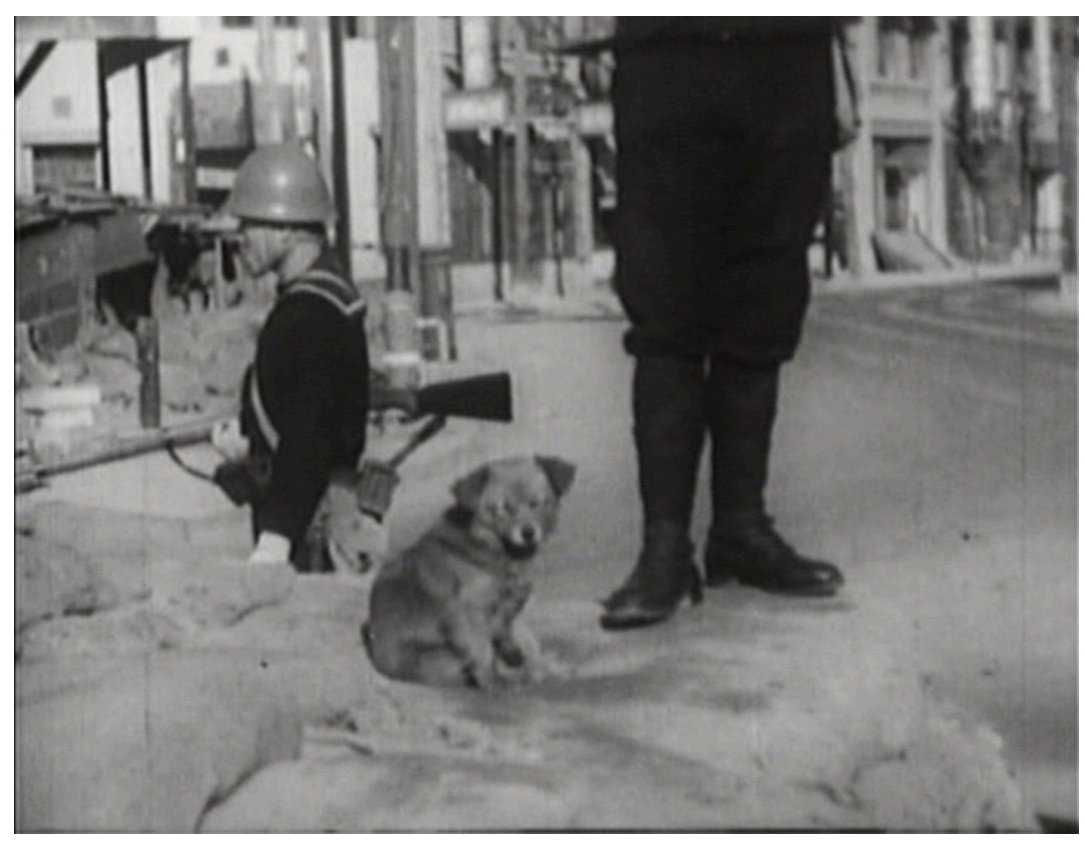

F3. Shanhai (Kamei Fumio, 1938).

En síntesis, para finalizar tenemos que apuntar la ausencia del conflicto bélico, sustituido por lánguidas secuencias en el extrarradio de la ciudad que alternan planos generales de un paisaje desolador con trincheras y tumbas, y planos detalle de elementos de primera necesidad perdidos o de la naturaleza destruida, convirtiendo así la guerra en un espectro poético cuyo terror no está en la lucha sino en su resultado: la muerte.

\section{De la sala de montaje al campo de batalla}

En el momento en el que Kamei montaba estas dos primeras películas se estaban produciendo cambios en la industria cinematográfica japonesa. El más significativo fue la aparición de la figura del director y la necesidad de su presencia junto al cámara en el campo de batalla. Dentro de los numerosos debates al respecto, Kamei se posicionó de manera contundente: "Los camarógrafos solo ven las cosas a través del objetivo. Son como caballos con anteojeras. Estar a cargo de la cámara, eso es inevitable. 
Es por lo que el director es necesario, para ver el mundo de detrás y a los lados” (en Nornes, 2003, p. 157). No sin levantar polémica, Kamei se fue con Miki a la batalla de Wuhan (1938) para filmar Tatakau heitai, finalizada en 1939 pero no exhibida por temor del propio estudio a la Ley del Cine (y a la censura) que estaba a punto de llegar. El film fue suprimido y las copias desaparecieron; hasta que fue encontrada una en 1975.

Tatakau heitai4 es un estertor del cine propagandístico que lleva más lejos la postura vista en Shanhai, siendo la humanidad de los soldados y los civiles el tema central. "Sin ningún tipo de planificación, los cámaras tendían a seguir la acción de la batalla, excluyendo la vida cotidiana de los soldados y las dificultades que conlleva la guerra” (Nornes, 2003, p. 159). Esto es precisamente lo que la figura del director Kamei y Tatakau heitai subvertirán. El film merece un análisis completo y detallado que aquí no podemos ofrecer, pero apuntaremos algunos de los elementos que lo hacen destacar y que provocaron su desaparición. De entrada, sorprende la supresión definitiva de la narración mediante voz over, dejando únicamente rótulos como guía para el espectador. Esto, sumado a la puesta en escena, el montaje y el uso de la música y el sonido directo acercan la película más a un drama de comienzos de la era sonora que a un documental.

La intención de Kamei era mostrar la crudeza de la guerra y el daño que provoca. El film se abre con una música elegíaca acompañada de un coro de voces. Un anciano chino reza frente a un pequeño santuario en el campo. $\mathrm{Su}$ casa en llamas. Primer plano del hombre, con mirada acusadora al espectador japonés (F4). Los aldeanos marchan en busca de un nuevo hogar. Tras ver lo que deja detrás el avance nos unimos al ejercito. La primera imagen de éste es un primer plano de la bandera japonesa pasando por delante de casas en ruinas. Unos soldados inquieren a un granjero: “Tengo treinta años. Tengo dos hijos. Quiero irme a casa”, dice. Estas imágenes no deja en buen lugar la imagen de Japón y el comienzo ya era más que previsiblemente censurable.

4 Este es uno de los pocos films de Kamei disponibles en streaming: http://www.tudou.com/programs/view/M7QW1iCHbXg 


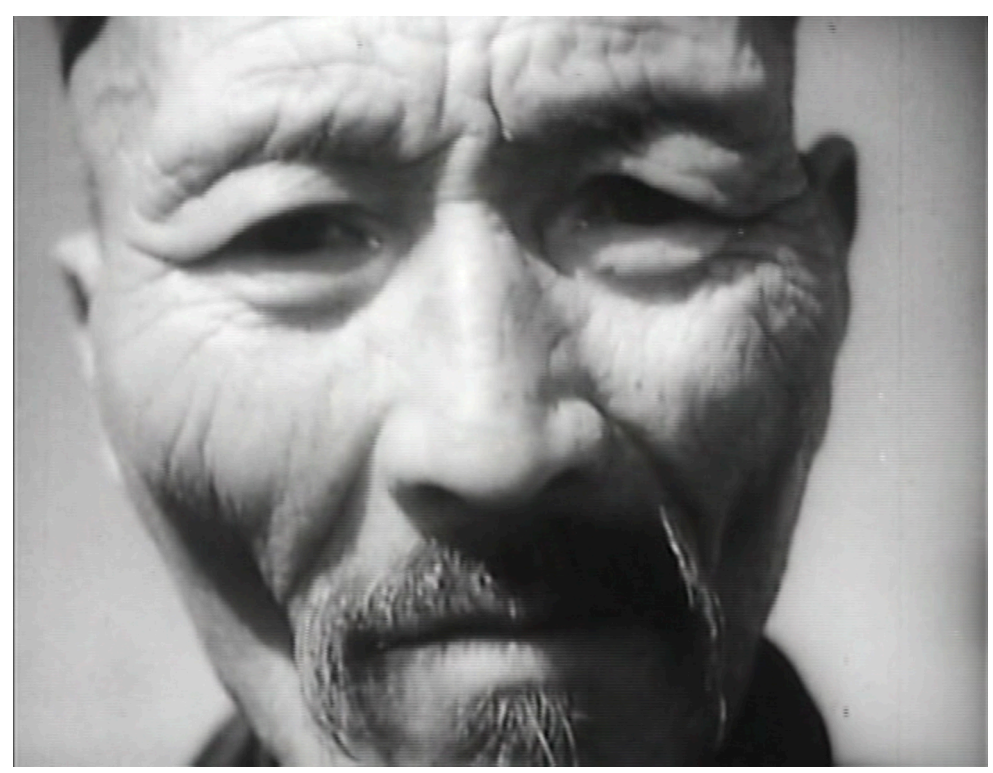

F4. Tatakau heitai (Kamei Fumio, 1939).

Como en Shanhai la guerra siempre queda fuera de campo. Cuando el ejercito llega a Wuhan, no sin antes sufrir muchos inconvenientes que reflejan el absurdo de la contienda (el cambio de ruedas por pinchazo de un coche, la construcción de un puente, un coche encallado en un río, soldados corriendo detrás de carretas...), en un gran plano general apenas vemos a los soldados moverse con el sonido de disparos de fondo. Un rótulo dice: "El día que las fuerzas anti-japonesas de Wuhan se desmoronan”. Y aparece en un primerísimo primer plano la Bandera del Kuomintang, el Partido Nacionalista Chino. Seguidamente, las ruinas de Wuhan.

Un plano-secuencia de diez minutos dentro de la caseta de un comandante del ejercito japonés es el momento más representativo y poderoso al respecto del fuera de campo. Como si de una ficción se tratara, la cuidadosamente planificada puesta en escena deja la puerta de entrada a la derecha y la mesa del militar a la izquierda, la guerra no cesa al otro lado de las paredes, los soldados van y vienen con noticias del avance, el comandante va replanteando la estrategia (les escuchamos gracias al sonido directo) ( $\mathrm{F}_{5}$ ) . Al final todos marchan, dejando la caseta vacía y el sonido de los disparos llenando el espacio. 


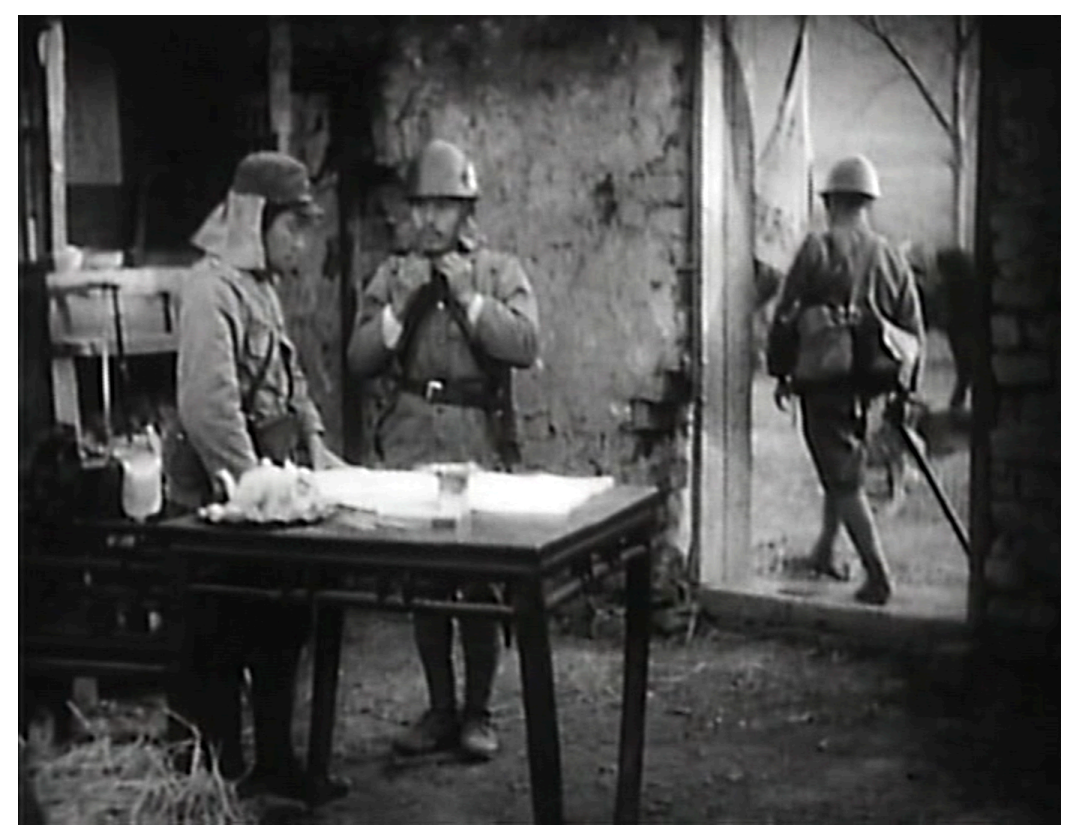

F5. Tatakau heitai (Kamei Fumio, 1939).

Respecto al acercamiento a la narrativa de ficción, destaca una secuencia rayana con el melodrama. Un grupo de soldados, sentados frente a un pequeño altar en memoria de su compañero perecido, leen la carta que su mujer envió y no llegó a tiempo. La voz (over) que escuchamos es la de su esposa, acompañada de una emotiva música. El montaje se alterna con planos de objetos personales del fallecido y una foto de sus hijos (F6). "Esta estrategia crea nebulosidad en la construcción de la película y dirige a los espectadores a una lectura que se resiste a la aceptación -al deseo- de la muerte en sacrificio [del emperador]” (Nornes, 2003, p. 171).

Nuevamente debemos recalcar el plano que cierra el film, que si bien la película termina con las convencionales imágenes de los acorazados por mar entrando en el puerto, Kamei ha puesto la guinda justo antes con varios planos de ciudadanos comenzando a recuperar la ciudad de las ruinas, y poniendo el punto y final con un niño pequeño sujetando a un cachorro en brazos y mirando a cámara. Esto busca ser un símbolo de la esperanza de un pueblo que después de la desgracia volverá a renacer, un mensaje de que las guerras pueden destruir ciudades pero no civilizaciones ni culturas. 


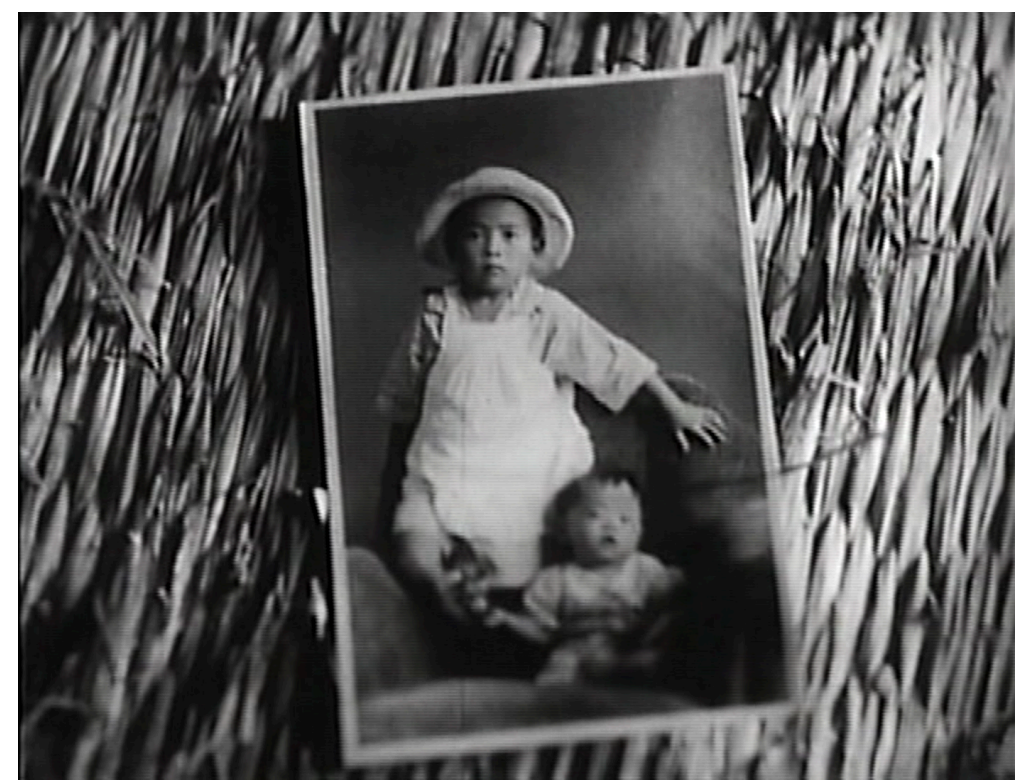

F6. “Toda la familia está bien, así que por favor no te preocupes. Más que nada ten paciencia, y trabaja duramente para cumplir con $\mathrm{Su}$ Majestad el Emperador", escribe la esposa del soldado para cerrar la carta. Tatakau heitai (Kamei Fumio, 1939).

\section{Problemas con la censura}

Tras el pulso a la industria que fue Tatakau heitai, Kamei fue relegado a la realización de un documental turístico sobre la prefectura de Nagano. El cineasta planteó una trilogía para Toho Studio. La segunda parte, Kobayashi Issa (1941) inspirada en la poesía del budista homónimo no fue reconocida por el Ministerio de Educación. El exceso de poética y mostrar la realidad de la vida rural en Japón: "desesperadas condiciones de vida y hambre" (Nornes, 2003, p. 175), alejaban al film de todo aspecto turístico y lo convertían en una nueva crítica desgarradora que no podía ver la luz. Kamei desistió de realizar la tercer entrega.

Otro encuentro con la productora, al negarse a cambiar el final de Fuji no chishitsu (Akimoto Takeshi, 1940), un documental científico en el que colaboró en el guión y el montaje, provocó su desaparición de los créditos. La película terminaba comparando el bello monte Fuji con el viejo monte Aitaka, un volcán desfigurado por las erosiones y la lava, diciendo que en algún momento el Fuji sería como éste y que mediante este contraste el espectador puede aprender mucho acerca de las leyes de la naturaleza. 
Querer desfigurar al símbolo de Japón tampoco estaba bien visto.

En 1941 Kamei fue arrestado por violar la Ley de Preservación de la Paz, y ser así el primer director en perder su licencia bajo la nueva Ley del Cine de 1939. Un sumario interno del gobierno recoge:

estudió cine proletario. [...] Kamei ha afirmado que la ficción comercial es un cine de entretenimiento burgués, historias de amor no realistas, y que promueven la evasión de la realidad en la gente corriente. [...] ha expuesto de manera indirecta la miserable situación de los campesinos de Shinano y la hipócrita vida de lo curas del Templo Zenkoji en Kobayashi Issa. [...] Además ha promovido el surgimiento de una conciencia contra la guerra (en Nornes, 2003, p. 177).

En 1943 salió de prisión. Tras denegarle el permiso para poder trabajar en la Manchurian Motion Picture Association, finalmente entró en una pequeña productora de Kyoto llamada Dentsu. Para ello debió superar el nuevo examen de dirección cinematográfica. A las películas que aquí realizó es difícil seguirles la pista, pues tras su detención la figura de Kamei comenzó a ser desprestigiada. Combinó la realización de documentales con el cine de ficción, en la mayoría de los casos para hacer películas de propaganda. De esta mezcla surge Seiku (1945), película sobre la aviación japonesa para concienciar a los niños de su implicación en la guerra. El film nunca se hizo público debido a la inminente derrota nipona. Además de ser un estrépito en todos los sentidos, ya desde la fase de producción. La versión final contaba con "un terrible sonido rugoso [...]. El montaje [...] sorprendentemente torpe" (Nornes, 2003, p. 180). Contemplando la filmografía de Kamei y su actitud siempre a la contra solo se entiende este resultado de una forma: un boicot a la industria desde dentro. Hasta 1997 el film no se pudo ver.

Tras la Segunda Guerra Mundial, gracias a estos trabajos desagradecidos, el amparo del productor, crítico e historiador Akira Iwasaki y la presión del jefe de la Sección de Cine y Televisión durante el periodo de ocupación norteamericana, David Conde, a la productora Nichiei, Kamei pudo llevar a 
cabo Nihon no higeki (1946). Para ello contaría con los más de quince años de metraje que Nichiei guardaba en su librería.

Esta película supone una nueva etapa en la filmografía de Kamei. El trabajo con found-footage le permite darle un nuevo (y radical) giro a las imágenes en el montaje. La poeticidad del periodo bélico ha desaparecido. El discurso es directo y agresivo, como la voz narradora que recorre todo el relato, desde el auge del imperio japonés por China, Corea y Filipinas, hasta su claudicación tras la Segunda Guerra Mundial. A través de periódicos y discursos, las imágenes que tenían como objetivo informar a la población, ahora son un elemento de crítica constructivista y acusación. Kamei no es amedrenta y ponen nombres y apellidos a los causantes de esta tragedia de Japón a lo largo del siglo XX.

El comienzo del film es una declaración de intenciones. El título aparece sobreimpreso en lo que parece una sala de juzgados, o el congreso vacío. En todo caso, la enunciación es clara: sentar a los acusados frente al espectador. Sigue un mapa animado donde cuchillos se clavan en aquellos lugares colonizados por Japón, tiñéndolos de sangre. Y se nos explica cómo la economía invertida en la industria militar deja al campo japonés en la miseria, mostrando como imagen alegórica a un caballo famélico.

Los años pasan y las guerras se tornan más cruentas. Kamei, por primera vez, decide incluir en el montaje imágenes del conflicto y del horror. Muestra tanto la matanza de civiles filipinos por parte de soldados japoneses, como la muerte de los kamikazes nipones para defender a su emperador. Un emperador, Hirohito, al que finalizada la Segunda Guerra Mundial, Kamei se toma la libertad de convertirlo en un civil más mediante el uso de un fundido encadenado (F7).

Ni siquiera bajo el control de la ocupación norteamericana el film tuvo una salida fácil. Nichiei tuvo problemas con las grandes distribuidoras. "Un informe indica que las compañías lo rechazaron distribuir por miedo a audiencias hostiles" (Nornes, 2003, p. 190). Finalmente se pudo ver en pequeñas salas independientes de los suburbios de Tokyo. Finalmente, tras 
un nuevo visionado por parte del Destacamento Civil de Censura la película fue secuestrada.

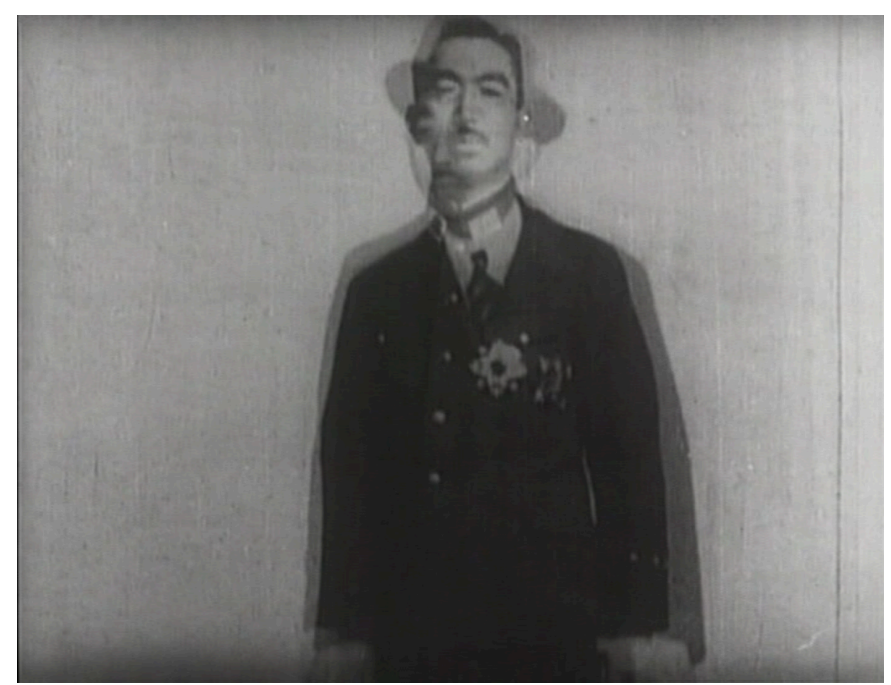

F7. Nihon no higeki (Kamei Fumio, 1946).

Para seguir en la industria a Kamei no le quedó más remedio que pasarse a la ficción. En 1947, junto a Yamamoto Satsuo, Kamei realizó Sensō to heiwa. A esta le siguieron tres películas cuyo tema central era las duras condiciones de vida de la mujer en la sociedad japonesa. Todas tuvieron problemas de producción, sufrieron la censura y continuas disputas con Toho Studio. Destaca On'na hitori daichi wo Yuku (1953). Tras este trabajo Kamei fue retirado de la producción de largometrajes.

\section{El sufrimiento posnuclear}

El polémico cineasta todavía no había dicho su última palabra. De manera independiente fundó la productora Nihon Dokyumento Firumu [Japón Películas Documentales] y realizó una serie de películas sobre las consecuencias de los bombardeos nucleares. Hemos podido acceder a Sekai wa kyōfu suru - shinohai no shōtai (1957) ${ }^{5}$. "Es deliberadamente sensacionalista, un mensaje de terror utilizando todo tipo de recursos retóricos. [...] Envuelto en justa indignación, él [Kamei] solo está interesado en apuntar con el dedo acusador" (Richie, 2009, p. 25-26). Si bien estas

5 https://www.youtube.com/watch?v=yCk2Qf6RA_s\&feature=youtu.be 
declaraciones de Richie son acordes al film, también podemos ver en ellas la actitud que los trabajos de Kamei han recibido en la mayoría de análisis occidentales.

Pese a iniciarse con unos créditos terroríficos donde el título está sobreimpresionado en imágenes de cuerpos con la piel derretida y una música escalofriante, la película es una larga sucesión de experimentos sobre la radioactividad: su larga permanencia en la atmosfera y las consecuencias en los seres vivos. Todos ellos filmados y narrados de la forma más científica posible sin gran interés cinematográfico. Vemos como se estudian sus efectos en canarios, ratones, conejos, la tierra, etc. En varias ocasiones se habla de Estados Unidos y el lanzamiento de las bombas, para dejar bien claro quien fue el causante. Finalmente, Kamei recurre al "objeto fílmico" más puro: los niños y como sufren la radiación: continuos exámenes médicos, deformaciones, falta de ayudas del gobierno para las familias, etc.

El documental muestra imágenes que no son agradables pero que son necesarias. El momento más abrumador para el espectador es la aparición de unas radiografías de un embrión con dos cabezas, seguidas de la imagen de un bebé con dos cuerpos pegados en uno (F8). Más adelante también veremos a un bebé que sufre de ciclopía.

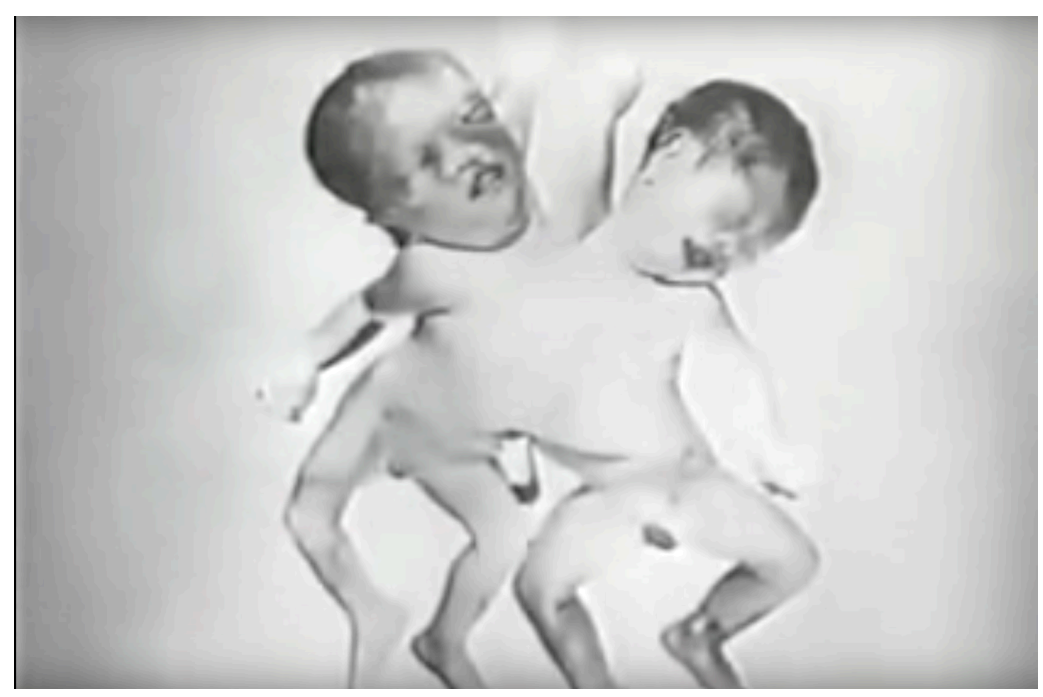

F8. Sekai wa kyōfu suru - shinohai no shōtai (Kamei Fumio, 1957). 
En estas películas los fuera de campo dan miedo: una panorámica vertical pasa de mostrar a un par de canarios falleciendo por culpa de la radioactividad a contemplar su pequeño columpio todavía balanceándose. Y las metáforas son cuasi maquiavélicas: unos científicos inyectan radioactividad en un conejo. El siguiente plano son niños de un colegio en una posición idéntica a la cobaya, sugiriendo lo que luego se verá: constantes pruebas médicas y un tratamiento de los niños como objeto de análisis científico.

\section{Conclusión. Una lucha constante}

La etapa final de Kamei fue extraña, probablemente debido a su interés por seguir haciendo un cine crítico y social, y la necesidad de comer cada día. Así, su siguiente película, Ningen mina kyodai (1960), consistió en un documental sobre la discriminación a los burakumin, la clase más baja de Japón. En contraste, su penúltimo film, Nihon no tsubasa (1966) fue un encargo de Japan Airlanes para promocionarse. Veinte años después, en 1986, completó su última película justo antes de morir: Ikimono mina tomodachi - Tori mushi sakana no komoriuta. "Este trabajo sobre los problemas ambientales relacionados con la destrucción de la tierra fue su mensaje de despedida” (Makino, 1995).

Kamei Fumio fue un cineasta incisivo, crítico e innovador, no exento de contradicción. Montador convertido a cineasta, utilizo la metáfora y el constructivismo como herramientas de distanciamiento, sacudida y reflexión para el espectador. Como humanista y antibelicista, sus películas buscaron ser al antítesis del cine de propaganda del cual intento ser un estertor. Siempre cercano al individuo maltratado por la guerra o las malas políticas gubernamentales, en un periodo de corrosiva censura tuvo que pagar las consecuencias de su atrevimiento y, además de ser conminado a trabajos de encargo, intento ser ocultado de la historia del cine de su país. 
Kamei Fumio es el reflejo de personas e historias que han sufrido constantemente la censura y el olvido. La mayoría de sus películas fueron confiscadas, secuestradas, hasta hace relativamente poco. Otras continúan siendo inaccesibles. Esto no le desanimó para luchar por hacer el cine en el que creía desde sus inicios hasta su muerte, sin temor a la represión. Su recuerdo nos pone sobre aviso de que la historia del cine todavía no está escrita y que gracias a las nuevas herramientas de restauración, conservación y análisis aún hay mucho cine que recuperar y devolver a su correspondiente lugar. Es tiempo de buscar nuevas miradas ocultas.

\section{Referencias bibliográficas}

Centeno, M. (2015). El redescubrimiento del cine documental japonés. El estudio contemporáneo de la desconocida obra de Susumu Hani en Iwanami Eiga. En A. Lozano (Ed.), El Japón Contemporáneo. Una aproximación desde los Estudios Culturales. Barcelona: Ediciones Bellaterra.

Eisenstein, S. M., Pudovkin, V. I. et alii (1928). Manifiesto del contrapunto sonoro. 〈http://soloparagourmets.blogspot.kr/2011/07/manifiestodel-contrapunto-sonoro.html\#.Vi-SYdar_NJ> [25-10-2015]

Kamei, F. \& Makino, M. (2009) Documentarists of Japan, No. 6: Kamei Fumio. Documentary Box. 27-4-1995. Recuperada de 〈http://www.yidff.jp/docbox/6/box6-2-e.html〉 [27-10-2015]

Matson, Yuji (2007). The World and The Image: Collaborations between Abe Kôbô and Teshigahara Hiroshi. Tesis doctoral. Victoria: University of Victoria.

Moya, M. (2000). Las películas documentales de Mantetsu durante la ocupación japonesa de Manchuria (1931-45). La ardua tarea de representar el paraíso en un marco de conflicto. Congreso ALADAA. Rio de Janeiro. Recuperado de: 〈http://bibliotecavirtual.clacso.org.ar/ar/libros/aladaa/moya.rtf〉 [23-10-2015]

Medvedkin, A. (1973). El cine como propaganda política. 294 días sobre ruedas. Córdoba: Siglo XXI Argentina Editores S. A.

Nornes, A.M. (2001). The typical Genius of Kamei Fumio. Kamei Fumio Retrospective. Tokyo: Yamagata International Documentary Film Festival.

Nornes, A.M. (2003). Japanese Documentary Film. The Meiji era through Hiroshima. Mineapolis: University of Minesota Press.

Richie, D. (2009). "Mono no aware": Hiroshima in Film. En M. Broderick 
(ed.), Hibakusha Cinema. Hiroshima, Nagasaki and the Nucler Image in Japanese Film (pp. 20-38). Oxon: Routledge.

Sedeño Valdellós, A.M. (2002). Cine japonés: tradición y condicionantes creativos actuales. Una revisión histórica. Historia y Comunicación Social, 7, 253-266.

VV.AA. (2005). El cine de los mil años. Una aproximación histórica y estética al cine documental japonés (1945-2005). Navarra: Gobierno de Navarra.

Cómo citar: Samit, A. T. (2017). "Kamei Fumio. Sombras, miserias y censura en el cine documental japonés”. Fotocinema. Revista científica de cine $y$ fotografía, $\mathrm{n}^{\mathrm{o}}$ 14, pp. 295-312. Disponible: http://www.revistafotocinema.com/ 